\section{THERAPY OF VERATRUM VIRIDE.}

Read before the Pennsylvania state Medical Society, 1895. BY JOHN M. BATTEN, M.D.

PIITSBURGH, PA.

Veratrum viride slows the heart's action and makes it more feeble. It was first used by Magendie and Andral in physiologic experiments in 1821. Meisner first discovered it in the seeds of veratrum sabadilla in 1818. Bardsley first used it in rheumatism and dropsy in 1826. The curative effect of veratrum viride lies in its influence on the heart to retard its action in acute inflammatory diseases wherein the pulsation is very much accelerated. I have been able to produce the physiologic effects of the drug in cases of inflammatory diseases with a dose of Norwood's tincture not larger than three drops every three hours. By this dose I have been enabled to reduce the pulse beat twenty or thirty in a minute, especially when the high pulse rate has been caused by inflammation. In inflammatory rheumatism I have had good results with this drug by keeping the pulse at or near normal until convalescence began. In the early stages of measles, scarlet fever, and in some cases of smallpox, it acts favorably in governing the heart's action. In typhoid fever where the heart's action is irregular, I have thought that this drug in one drop doses aided in steadying it. For this purpose $I$ have in the treatment of typhoid fever continued the drug in one drop doses until convalescence set in. In all acute inflammatory diseases of the chest it is an excellent remedy; in acute pneumonia, pleuro-pneumonia and pleurisy. If in acute pneumonia the pulse can be kept at or near normal by this drug in the stage of congestion, we may often be able to jugulate it or prevent it from entering upon the hepatized stage. Even in a sthenic case in the second stage veratrum viride acts well. The heart's action is lessened without loss of blood as in venesection.

"Should we Bleed or not Bleed in Acute Pneumonia?" was the title of a paper read by a gentleman before the American Medical Association at its session held in Milwaukee, Wis., in 1893. In the discussion of the paper opinions were diverse. One gentleman advocated veratrum viride in the treatment of acute pneumonia. He had such entire confidence in the treatment of the disease with this drug by keeping the pulse at or near normal, that he made the bold assertion that all cases could be jugulated, or cut short, by this mode of treatment.

Feb. 27, 1896, I attended William McC., male, aged 46. The disease (pneumonia) was about entering the second stage, both lungs were involved. The pulse was 82, temperature 102 degrees, respiration 32 . The expectoration bloody mucus. I prescrilied veratrum viride, three drops every three hours. February 28 , expectoration rusty, mixed with blood, temperature 101.5 degrees, respiration 30 , pulse 80 . I prescribed in addition to veratrum viride, gr. 1.40 of nitrate of strychnia every eight hours. February 29, temperature 99 degrees, respira tion 28 , pulse 79. Sputa less rusty. March 1 , pulse 78 , temperature 99.5 degrees, expectoration rusty. After this during the course of the disease, etc., neither the pulse nor temperature rose above normal. On March 5 the rusty sputa disappeared. On the 16th patient was sitting up in bed, and made rapid con valescence.

In the same house, on March 12, I attended a male aged 66 , entering the second stage of $\mathrm{ty}_{\mathrm{I}} \mathbf{b}$ id $\mathrm{I}_{\text {neumonia }}$; both lungs were involved. Tongue thickly covered with a brown coat, red around the border: delirious; temperature 103 degrees, respiration 30 , nulse 109 ; rusty sputa. I treated him in the same manner as the former ratient till the evening of March 15 , when he had an attack of heart failure. I withdrew the veratrum viride and substituted whisky, continuing the strych nia. From this time, during the course of the disease, the pulse did not rise above 90 . The respirations for four days after that of my first visit were $36,35,35$ and 38 respectively, then receded gradually. March 20 it was 30 , and in a few days down to 19 . The pulse became gradually slower, and March 22 it was below norma!. The patient had convalesced April 6.

The heart failure of the second case was caused by the cumulative effect of the veratrum viride. It is my opinion that the failure of the heart acted favorably on the course of the disease, as the turning point seemed to be established at this time. In both of the cases I enveloped the chest in oil silk jackets.

\section{RE-INFECTION IN CONSUMPTION.}

Read before the Mississippi Valley Medical Association, St. Paul, Sept. $16,1 \times 96$.

BY JOSEPH MUIR, M.D.

SENIOR PHYSICIAN TO THE NEW YORK THROAT AND LUNG HOSPITAL. NEW YORK.

That but a comparatively small percentage of consumptives actually succumb to a first attack of tuberculosis has been time and agrin demonstrated through necroscopic examinations. The question is no longer an open one. As a matter of statistics, indeed, not only is a first attack not fatal, but a large proportion of patients recover from it and their subsequent death is found to be due to causes disconnected with any pulmonary lesions. If that is so-if under reasonably auspicious circumstances there is a strong probability of a cure being effected where the lesion is yet in its initial stages, then to what cause or causes are subsequent relapses to be attributed?

The ordinary received idea of the re-development of the tubercle can not certainly explain all or even the major part of the phenomena, for in a large number of cases the bacilli are, by postmortem exuminations, found to have been utterly discharged from the body. There must, therefore, be some other explanation, and the following considerations are offered, not to announce an established certainty, but to suggest a theory that may serve to reconcile many of the seemingly inconsistent cases which the practitioner encounters in his daily practice.

In the first place, there can be no serious dispute that in the vast majority of instances primary infection is owing, not to inherited tendencies but to external conditions. Were this not so, the influence of environment on turberculous conditions would not be so palpable and important as it is.

Among the rich, where the luxuries of exceptional food and frequent change of air are always accessible, very few cases of consumption prove intractable. The advantages which they enjoy are so far sufficient to immunize the lung tissue against further attack, that a life time may pass without any advance being made by the virus. Frequently, indeed, a permanent cure is affected.

But among the poor the case is very different. The incessant struggle for life demands their presence in the dust-laden atmosphere of labor; in the badly ventilated sweat-shops; in the imperfectly drained tenements; in the clusely packed, squalid quarters of poverty. Every breath they draw, almost every particle of food they eat, contributes a little to the poison that renders the tubercle bucilli the dread of civilization. It is there, in these disease-laden districts, that primary infection takes place.

Then, in most cases, comes a period of comparative comfort at a hospital. The patient enjoys good food and fresh air, and the ravages of the dread destroyer 